\title{
Support and Nonsupport for Nationalist Rebellion: A Prospect Theory Approach
}

\author{
Daniel Masters \\ Department of Political Science, Marshall University
}

\begin{abstract}
Prospect theory has been advanced as one way to link intentional rebellious action and the influence of social conditions on individual decisions to support such action. This study extends the application of prospect theory by explaining tendencies toward action or inaction among individuals within identical social contexts. Put simply, the way in which people define reference points has an effect on how they perceive violent options. These perceptions may invoke inaction biases among members of a constituent community. This explanation is explored with illustrative examples drawn from interviews with individuals who supported or did not support rebellious action in Northern Ireland (in 1998) and in the West Bank and Gaza Strip (in 1999). The interview data suggest that territorial demands are an important factor in how rebellious options are perceived.
\end{abstract}

KEY WORDS: prospect theory, collective action, ethnonational rebellion, territoriality

Students of political behavior in general, and of violent behavior specifically, must at some point address the issue of participation versus nonparticipation. Participants in violent action engage in, or threaten, coercion for political ends. The costs of participation tend to be very high; the benefit of such action is a simple public good shared equally by all, regardless of whether they participate. As such, the tendency to free-ride on the efforts of others is strong, hence few participants seek the public good. However, to acquire the public good often requires that many people participate. Thus, the task facing rebels is to overcome free riding in order to acquire the public good.

In Mark Irving Lichbach's The Rebel's Dilemma (1995), the author identifies a series of solutions to the free-rider problem, all centering on how to alter costbenefit analysis in order to mobilize potential participants. One solution is referred to as "changing the type of public good" or "seeking public bads" (Lichbach, 1995, p. 107). In basic form, the solution suggests: "The initial task of the revo- 
lutionary organization is to adopt or construct a world view that ... communicates ... the understanding that existing . . . arrangements are worse than in some "normal past'" (Berejikian, 1992, p. 653). If people accept this view, they are more likely to accept risks associated with rebellious action, thus lowering the assumed high barriers to mobilization. This solution comes from prospect theory, a model of human decision-making that suggests that people overvalue losses relative to gains. Prospect theory posits that people are risk-averse when facing a choice between competing gains and risk-acceptant when facing choices between competing losses (Berejikian, 2002). Risk acceptance when facing losses, though, is contingent on how losses are defined versus the type of risks advocated for recovering losses (Baron \& Ritov, 1994).

The goal of this article is to advance an explanation of rebellious action that uses prospect theory to account for variation in risk acceptance between individuals from the same social situation. This explanation can also explain the linkages between individual perception and experiences, the rise of a constituent community, and the role of rebel organizations in mobilizing for and enabling rebellious action, while accounting for variable risk acceptance by individuals from similar social situations. The issues surrounding variable risk acceptance are illustrated with interview data collected from individuals supporting or withholding support for rebellious action in Northern Ireland and in the West Bank and Gaza Strip. The data show how individuals define goals and how these definitions affect the perception of rebellious options. The data also identify avenues for further research into reference point definition and rebellious action-namely, how to address the issue of territorial concession in rebellious situations.

\section{An Overview of Prospect Theory}

Prospect theory assumes that individuals are independent agents making deliberate choices that will lead to a desired outcome (McDermott, 1998). The course selected, however, is often influenced by how options are framed. The framing of a decision is important to whether options are defined as gains or losses, which has an impact on a person's propensity to accept or reject risk. Although individuals remain self-interested actors, their decisions take place within a dynamic environment that shapes the perception of alternatives.

To explain these tendencies, prospect theory points to three interrelated aspects of the decision process. First, people attach value to change in position rather than overall position, and the impact of change diminishes as it grows larger. This diminishing sensitivity to increasing gains and losses identifies two important elements regarding decisions: (a) People define their condition on the basis of a reference point, the anchor for any decision; and (b) as conditions change, people judge the value of change as compared to the reference point. As we move further away from the reference point, there is a marginal value of change (Kahneman \& Tversky, 1979; Levy, 2000). 


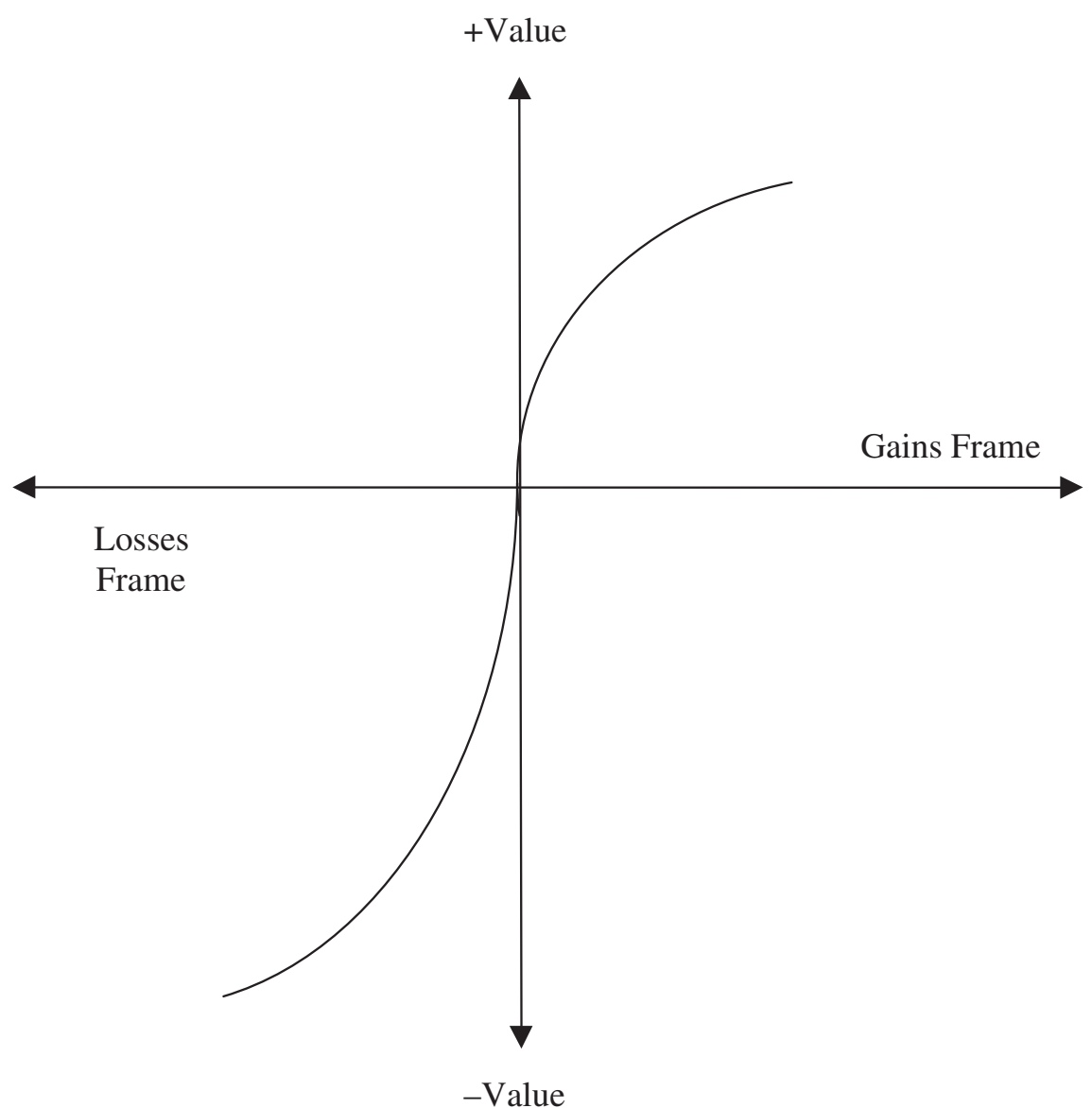

Figure 1. Subjective utility function for prospect theory.

The reference point is important for decisions because it defines how people will interpret change; change is assigned value as either gains or losses relative to the reference point. This relates to the second aspect of the decision process: People overvalue losses relative to gains of equal value. Because losses are overvalued, reactions to losses and gains differ. The behavior reflects a general predisposition to avoid losses; hence, people will engage in more risk, exert more effort, and persist over longer periods of time to avoid losses than to secure gains. Combining these two tendencies (diminishing sensitivity to change and loss aversion) implies a value function that is S-shaped and asymmetrical, with a concave curve in the domain of gains and a steeper convex curve in the domain of losses (Figure 1). The value function is derived from numerous experiments on 
decision-making that have demonstrated a consistent pattern of risk orientation across a variety of contexts and situations (Kahneman \& Tversky, 1979).

The asymmetry of losses and gains around the reference point has a critical effect on choice and risk orientation. This relates to the third aspect of the decision process, "framing effects" where alternative framing of options (as losses vs. gains; e.g., mortality vs. survival) contributes to a reversal of preferences (Tversky, Slovic, \& Kahneman, 1990, p. 215). Moreover, "a person who has not made peace with his losses is likely to accept gambles that would be unacceptable to him otherwise" (Kahneman \& Tversky, 1979, p. 287). Preference reversal is associated with framing, but only through the way options are weighted (Levy, 2000). Decision weights are subjective probability assessments that display strong patterns among individuals. Specifically, certain or impossible outcomes tend to receive the heaviest weight. Meanwhile, events that are unlikely are given more importance than they deserve, and events that are more likely are often given less importance than they deserve (McDermott, 1998, pp. 30-31). Combining loss aversion with framing and decision weights explains why people seek to avoid risk when facing choices over gains (accept sure gains over risky gains) but accept risks when facing choices over losses (gamble for improved conditions over accepting sure losses) (Levy, 2000).

Efforts to explain framing are not fully developed at this point. It is widely believed that framing arises in part from the way decisions are presented; however, norms, habits, and expectancies also have an impact (Tversky \& Kahneman, 1986). Habits tend to be particular to the individual, and norms are products of social processes; thus, they may be idiosyncratic but understandable. During the editing phase of the decision process, individuals analyze available prospects, resulting in simplification of a decision. Simplification occurs by coding, combining, and canceling alternatives to narrow the number of options while defining options as gains or losses. Once provided with a reasonable presentation of the decision (through internal editing or presented by outside actors), people tend to accept the formulation of options, hence the decision is not likely to be recast (Kahneman \& Tversky, 1979). This is important because it highlights a point where outside actors can manipulate decisions by way of presenting options to elicit a particular response (Maoz, 1990). Another important feature is segregation, where the decision-maker focuses on the factors most relevant to the immediate problem while failing to account for related outcomes (McDermott, 1998). This is important in rebellious choices, where people may be inclined to view the decision as related to change in personal and social conditions while ignoring related outcomes (such as worsening conditions or threats to personal safety). During the evaluation phase, edited prospects are assessed and the option with the highest value is chosen. The option with the highest value is defined by change and efforts to avoid losses. As such, the prospects are assessed on the basis of the anchor (reference point) and the potential for change to or from the reference point. 
In sum, prospect theory suggests that people are sensitive to change in the environment, or aspirations as to how the environment should look. This sensitivity can alter the ordering of preferences; this means that preferences and risk acceptance are not invariant across contexts. ${ }^{1}$ People tend to accept risk when choosing between losses because the risk offers the potential to escape losses altogether, not because of the perceived likelihood of success associated with the option or the need for some positive payoff (Berejikian, 1992).

There are two related issues that need attention: the effect of groups on biases in the decision process, and the impact of variable definition of losses on risk acceptance. Beginning with the former, evidence shows that groups tend to escalate risky commitments more than individuals do (Seibert \& Goltz, 2001; see also Kameda \& Davis, 1990). Research suggests that in small groups, polarization pushes people toward dominant (risk-acceptant) alternatives, increasing the strength of commitment for the alternative (Levi \& Whyte, 1997; Seibert \& Goltz, $2001) .^{2}$ Through group discussions, leaders can exert influence, magnifying riskacceptant positions and exposing all group members to arguments favoring such positions (Paese, Bieser, \& Tubbs, 1993)—especially in conditions where the decision task is not clearly defined and outcomes are nontransparent (Levi \& Whyte, 1997). This, combined with a desire by people to be perceived favorably when argumentation involves face-to-face discussions, creates a condition where members of the group internalize and reflect the majority position (McGuire, Kiesler, \& Siegel, 1987; Whyte, 1993).

The tendency to escalate risky commitments does not mean that all members of a group will favor risky options. Many individuals may oppose such decisions. This variation in risk acceptance relates to the dynamics of group decision-making and individual perceptions regarding losses and action. In the group, polarization typically occurs in conjunction with conformity pressures, leading to convergence around risk acceptance (Whyte, 1993). However, convergence and polarization are separate processes, and one does not require the other for risk escalation to occur. Some segments of the group can oppose risk escalation and decide to abide by the decision to avoid unnecessary confrontation (Levi \& Whyte, 1997). Furthermore, escalation toward risk is observed more within small groups. As group size grows large, convergence toward risk is less likely as the connections between members weaken. This is particularly important for larger ethnonational groups where group membership is determined by the identity of the individuals rather than by voluntary association.

We can speculate that in situations where connectedness between group members is loose, other factors influence risk escalation tendencies. In particular,

\footnotetext{
${ }^{1}$ This violates the invariance principle in classical rationality, whereby variations that have no impact on the outcomes should not affect individual preferences, meaning that risk acceptance is assumed to be consistent.

${ }^{2}$ The experimental evidence to this point involves small-group exercises. Much work needs to be done to verify whether these hypotheses apply to larger groups.
} 
perceptions regarding the value of losses play an important role. When two people are exposed to a similar situation, their reactions to it may be different because they have differing points of reference (Tversky \& Kahneman, 1981). Concomitant with this, we observe inaction or omission biases, where people may judge action as worse than inaction in certain circumstances even when inaction may result in new outcomes (i.e., changes in the status quo) (Schweitzer, 1994). Inaction biases are often thought to mean a preference for preserving the status quo. However, evidence suggests this is not the case. Rather, inaction is an artifact of an effort to avoid action, even when avoiding action results in a change in the status quo. As such, inaction is not dependent on status quo biases. Moreover, inaction biases are consistent with loss aversion, where commission (action) can represent a gain in one dimension and a loss in another when compared to the omission (inaction) default or reference point (Baron \& Ritov, 1994). Because losses hurt more than gains feel good, people tend to prefer omission.

The omission bias can manifest itself in many forms. Most relevant to rebellious behavior are "tradeoffs" (Baron \& Ritov, 1994), where inaction (nonviolent behavior) may be perceived as better than action (violence) designed to bring about an equally desirable outcome. Individuals are not assessing options exclusively on the framing of choices; they are assessing the form of action as well. As such, the act of rebellion may be perceived as contributing to losses (Baron $\&$ Ritov, 1994). Therefore, variation in risk acceptance is most likely related to the parallel effects of differing reference points and inaction (omission) biases among individuals.

\section{Prospect Theory and Rebellious Choices}

Prospect theory is useful for understanding rebellious choices because it allows us to account for contextual factors in the decision process in a way that is neither too simplistic nor unnesessarily complex. We do not assume that poor social conditions will automatically lead to rebellion; rather, we assume that individual perceptions of conditions relative to a reference point will shape a person's value-regarding alternatives, affecting risk orientation. This suggests that when "the reference point is not congruent with the status quo [losses domain] ... [it] is destabilizing and reinforces movement away from the status quo" (Levy, 1997, p. 91). For these perceptions to translate into action, they must be widely shared and must be useful for framing rebellious choices. By using prospect theory, we can construct an explanation for rebellious behavior that connects social conditions with individual decision-making while accouting for the role of rebel organizations as mobilizing agents.

Consider the following illustrations. Countries A and B have minority ethnic populations with expectations of self-determination (autonomy of some form). This expectation forms the reference point for rebellious decisions. In country A, 
the government offers local autonomy to the group. Autonomy is less desirable than independence, but it is more desirable than subjugation to the majority group. In this situation, status quo conditions approximate the reference point of the minority group, reinforcing the status quo and enhancing stability in society. The decision to rebel is perceived as a choice between competing gains: one certain, the other risky. In this situation, people are inclined toward risk-averse behavior and would likely reject rebellion. This is not to assume that rebellious action will not happen; rather, if it does occur, it is not likely to gather widespread support. In country $\mathrm{B}$, the minority group is subjugated to the majority population. There is little effort by the government to address self-determination. In this case, status quo conditions fall below the reference point of self-determination (a losses frame). Here the status quo conditions are not congruent with the reference point, thereby destabilizing the status quo as it reinforces movement away from it. A decision to rebel in this situation is perceived as a choice between competing losses: one certain, the other risky. In such a situation, people are risk-seeking and are more inclined to rebellious action. This is not to assume that rebellion will occur; rather, if rebellious action is promoted by a group, it is more likely to gather support to achieve the public good.

These examples demonstrate a basic way in which prospect theory can explain the occurrence of rebellious action. However, this application is very simplistic. As such, it leaves the explanation vulnerable to criticisms such as "Most individuals care more about their own welfare and survival than about public policy or the ideology of the society" (Olson, 1990, p. 13). Although such a criticism remains true, prospect theory does not assume that people will accept rebellion in order to better society as a whole. Rather, people are more likely to accept risks they would otherwise reject when they come to see losses as personally meaningful, when personal losses are tied to group conditions, and when rebellious action is framed as an option to escape losses.

Individuals may come to see losses as personally meaningful through any number of avenues. Potential paths include personal experiences, socialization, and the impact of significant incidents. Personal experiences refer to the degree to which an individual is directly affected by the conditions of subjugation by an opposition group. Conditions such as job discrimination, housing discrimination, arbitrary arrest, and concentrated poverty bring awareness to individuals that conflict with another group exists; hence, these conditions represent a loss. Socialization refers to the role of families in influencing one's perception of losses. Families that support rebel activity are likely to teach children to view the social condition in a way that would highlight perceived losses, and to view rebellious action as an appropriate solution to overcome these losses. Finally, the impact of significant incidents plays a role. In conflict situations, it is likely that certain events (e.g., massacres) will occur that mobilize large numbers of people into action. These events temporarily intensify perceived losses, thereby increasing the number of people willing to accept risk. 
These experiences lead individuals to see their personal condition as one defined by losses, but individual-level experiences will not necessarily translate into organized rebellious action. Rebellious action is more likely to occur when experiences are concentrated among members of a solidary group-that is, when individual experiences are linked to a pattern of group experiences. Such solidary groups take many forms, but the key feature is that members perceive themselves as affiliates of a distinct community leading to the social construction of "we" and the emergence of group interests (Hall, 1993). A threat to these interests provokes group responses, not individual responses (Tilly, 1978). The connections among group members tend to be stronger when the basis of identity is nationality or ethnicity. Cultural identity groups tend to have more enduring linkages between individuals (Gurr, 1996). If the cultural group experiences shared grievances about unequal treatment, this is likely to galvanize the community, thereby making mobilization easier (Gurr, 1996; see also Tilly, 1978). Also as prospect theory suggests, the perception of loss concentrated among group members increases the potential for risk escalation. However, this does not mean that rebellious choices will necessarily be defined or acted upon. In essence, when losses are concentrated among members of the solidary group, we see the emergence of a "constituent community" that an entrepreneur can draw upon to organize for collective action.

The key element that transfers an increasingly risk-acceptant (constituent) population into one that mobilizes for collective rebellion is organization, or the rebel group. Rebel organizations perform many different tasks important to the mobilization effort. Some tasks include framing of rebellious choices and pooling/directing resources for rebellious action. Framing rebellious options consists of providing an interpretive schema that simplifies and condenses the world by selectively punctuating and encoding objects, situations, events, experiences, and sequences of action within the environment (Snow \& Benford, 1992). The frame presented by rebels serves to link individuals (as potential participants) to the rebel group (mobilizing agent) by providing beliefs and values that are congruent with and complementary to the goals of the group (Snow, Rochford, Worden, \& Benford, 1986). The frame then serves as a "mode of attribution" by presenting a less than perfect picture of reality while providing a plan of action to correct the situation (Snow \& Benford, 1992, p. 137). In sum, the organization (as part of its mobilization effort) constructs a worldview that frames individual experiences within the context of group experiences related to an overall social condition, while also presenting the decision to rebel as one where people can accept current conditions (defined as a sure loss) or engage in some form of collective effort (e.g., rebellion) to escape the condition (gamble to recover/escape losses).

Implied within the decision are two potential outcomes: Social conditions may degrade in the short term, and rebellious action may threaten personal safety. However, segregation (as explained above) means that individuals are likely to 
ignore these relevant outcomes. For example, degrading conditions are likely to be integrated into an evaluation of the status quo, thereby reinforcing the perception of existing losses. Furthermore, within this context (in the interaction in the rebel group and between entrepreneurs and the community), we are likely to observe polarization of positions toward risk escalation.

Concomitant with the framing effort is pooling or directing resources for rebellious action. In the course of mobilizing people to support rebellion, resources are gathered (labor, money, and other material resources) that are then directed toward action. Thus, by mobilizing people through framing efforts, the organization is able to provide participants with resources that enable participation. The gist is that people cannot participate without the means to do so (Lichbach, 1995). Therefore, soldiers must be equipped and given access to the means to allow their participation. The ability to provide those resources requires members of the constituent community to share the burdens involved with rebellious activity. Such burden-sharing does not require all people to take up arms; rather, it is likely to require contributions through payments to a pool of resources directed toward rebellious activity.

Last, we cannot assume that membership in solidary groups or successful framing of rebellious choices will mobilize all individuals in a constituent community to support rebellion. Despite the notion that cultural communities possess stronger and more enduring linkages between individuals, these connections are not as strong as they would be between members of smaller, tight-knit voluntary associations. As such, convergence toward risk escalation may occur among some segments of the community, but divergence from risk escalation is likely among others as well. Factors related to individual experiences, socialization, and perceptions of history may affect people's perceptions of social conditions, goals, and actions. Ultimately, the difference between individuals supporting rebellious activity and those withholding support will manifest itself in how reference points are defined and how actions taken to recover perceived losses are assessed.

In short, all members of a constituent community are likely to define the status quo in terms of losses, but they way in which goals are defined may differ slightly. The difference in how goals are defined can relate to risk acceptance by way of producing inaction, whereby some individuals may assess violent action in terms of a tradeoff. The tradeoff is that people may perceive violence as a loss relative to their reference point, creating a preference for inaction in the form of nonviolent behavior (e.g., protest demonstrations and/or negotiated solutions) to recover losses. Inaction here results from people expecting greater regret for the bad effects of action than the worse outcome that may result from inaction. Acts appear more causal than inaction, and blame for an outcome depends on the perception of causality (Ritov \& Baron, 1995, p. 119). For others, the reference point may be defined in such a way that violent action is deemed an appropriate risk for recovering losses, and is viewed as separate from the worsening conditions related to rebellious action. 


\section{Illustrative Examples}

The explanation of collective action laid out here suggests that many factors are important to the occurrence of rebellion. Among these: perceptions of social conditions as incongruent with individual reference points; perceived losses widely shared among members of a constituent community; activities by rebels to frame rebellious decisions as an option for escaping losses; and gathering and directing resources for the rebellious effort. At the same time, individuals in a constituent community may not define reference points equally, invoking inaction biases. This section explores some of these issues with the use of illustrative examples drawn from Northern Ireland and the West Bank and Gaza Strip. Space limitations prevent full exploration of the theory of collective action presented here. As such, the data presented focus specifically on reference point definition among those who support or withhold support for violent action and how the definition of the reference point relates to assessments of violent options.

The cases were chosen for a number of reasons. Foremost, they are similar with respect to the nationalist content; that is to say, the goal is to affect national self-determination for a constituent ethnic community. The specific goals of the groups vary. For example, in Northern Ireland, the Republican movement (represented by Sinn Féin and the Provisional Irish Republican Army) seeks to overcome partition of Ireland put in place after the Black and Tan War of 1919-1921. In Palestine, some groups - the Popular Front for the Liberation of Palestine (PFLP), Harakart al-Muqawma al-Islamiyya (Hamas), and Islamic Jihad-seek a goal similar to that of the Republican movement: to establish Palestinian-Arab control over all the territory of historical Palestine. Other groups-Fatah (the most prominent faction of the PLO) and the Democratic Front for the Liberation of Palestine (DFLP) — seek to end Israeli occupation of the West Bank and Gaza Strip, using the 1949 armistice lines (the so-called "pre-1967 borders") to define a border between Israel and a new Palestinian state. Both cases are similar in recent efforts to end violent conflict and engage in peace processes to address nationalist goals. The effort has been sustained in Northern Ireland to a degree, whereas it has collapsed in Palestine. The time frame for the data collection precedes the collapse of the peace process in Palestine. Collecting data during the peace processes offers an opportunity to assess individual perceptions regarding change through the peace process, which may or may not affect an individual's willingness to accept or reject violent options in the future.

The data for this study consist of interviews with individuals from Belfast (1998) and the West Bank and Gaza Strip (1999). A total of 82 respondents were interviewed, 42 from Belfast and 40 from the West Bank and Gaza. Seventy-one respondents identified themselves as supporters (engaged in or offering support for violent action), and 11 identified themselves as nonsupporters (opposed to violent action, favoring other activities such as protest demonstration and nego- 
tiation). ${ }^{3}$ The interview questions were drawn from an interview schedule to assess factors of mobilization for rebellious action. The complete schedule includes questions regarding various material incentives, community and family pressures, and potential coercive sanctions. The questions included in this article are designed to specifically assess individual reference points and risk acceptance (see the Appendix).

Individuals selected for the study followed a nonprobability design, or convenience sample. ${ }^{4}$ As such, the data do not provide results that are generalizable to a larger population in either case or to rebellious phenomena in general. Instead, the data are used as illustrations of reference levels and risk acceptance or rejection. ${ }^{5}$ Thus, the data do not serve as a test of prospect theory. The sensitive nature of individual activities does not allow a researcher to use standard pretest-posttest framing measures or other experimental controls needed for rigorous testing of the theory. However, the evidence provided does offer insights into how people within nationalist communities vary in the perceptions of issues in a conflict and how this translates into a decision to support violent action.

\section{Defining Reference Points}

Alternatives chosen by individuals are determined by the value function in conjunction with the decision weight attached to various options. The way in which decision weights are assigned does not change with the frame. But the

\footnotetext{
${ }^{3}$ The sample focused on the masses within the nationalist communities rather than relying on elite sampling. The characteristics break down as follows: 46 supporters were male and 25 were female; 5 nonsupporters were male and 6 were female. Fifty-one supporters had a college education and 20 did not, whereas all nonsupporters had a college education. Thirty-four supporters held professional jobs and 37 held nonprofessional jobs, versus 8 and 3 for nonsupporters, respectively. Sixty-eight supporters claimed the dominant religion (Catholic for Northern Ireland, Islam for Palestine) and three claimed a nondominant religion (Protestant for Northern Ireland, Christian for Palestine), whereas eight nonsupporters claimed the dominant religion and three claimed a nondominant religion. Finally, 60 supporters claimed the dominant national identity (Irish for Northern Ireland and Palestinian Arab for Palestine) and 11 claimed a nondominant identity (Northern Irish for Northern Ireland and Arab for Palestine), whereas nine nonsupporters claimed the dominant national identity and two claimed a nondominant identity.

${ }^{4}$ The sampling technique is a compromise made to accommodate the need for trust between the interviewer and respondent. In terrorist support networks, individuals are not willing to openly discuss their activities and beliefs with people they do not know or trust. Thus, the interviewer must make contacts with individuals who will vouch for his or her integrity. Respondents are more willing to discuss sensitive topics with an interviewer if a trusted person has referred the interviewer.

${ }^{5}$ A note of caution is necessary. When applied to empirical settings, prospect theory is vulnerable to causal relationship problems. Researchers in experimental settings can rely on randomly selected groups to control for inherent risk orientation in an individual. Outside the experimental setting, researchers do not have the same luxury. This suggests that a potential intervening factor may existthe possibility that individuals included in the study may be naturally predisposed to risk and therefore choose risky behavior, concomitantly setting high goals indicating a domain of losses. This means that the relationship between a losses domain and rebellious action may be spurious, as risk orientation is more a function of individual characteristics and not related to framing.
} 
context does influence how weights are treated. This affects the attractiveness of different options in different contexts. Moreover, the tendency to avoid losses remains constant; hence, the overweighted option in the situation is the one that offers the chance to avoid/escape losses, and when the decision frame results in a definition of options as between competing losses, risky options become attractive because they represent the potential to escape losses. Hence, perceptions of options extend from the frame of reference that people hold with respect to social conditions. Therefore, the anchor for the decision (the reference point) affects the frame of reference, in turn affecting the attractiveness of certain alternatives.

For example, the Republican movement in Northern Ireland seeks a unified Irish republic. On the assumption that this goal serves as the reference point, Irish respondents were asked to assess this statement of Republican goals: "To be a Republican means that I believe the only acceptable state of existence is a 32county (United) Ireland. Anything less is unsatisfactory and should be opposed." Respondents were asked whether the statement accurately portrayed Republicanism and whether it reflected their personal views. All those claiming to support violent alternatives (supporters) agreed that this statement accurately reflected the core belief of the Republican movement. Some respondents appended extra issues, none of which directly contradicted the core statement. For example:

"It is more than a geographical definition of territory. It would encompass all ideologies that oppose monarchical systems. In the case of this country it involves a breaking of imperialism. To end a colonial situation." (Northern Ireland 38)

In the Palestinian case, goals for different groups diverged in 1973-74 as Fatah and the DFLP promoted a two-state solution recognizing Israel along with an independent Palestinian state in the West Bank and Gaza (Smith, 1992). Meanwhile, the PFLP formed the "rejectionist front" pursuing reclamation of all Palestinian lands and disavowing the right of Israel to exist (Smith, 1992, p. 234). Islamic Jihad and Hamas joined the PFLP in the 1980s by favoring reclamation of all Palestinian lands but differed with the PFLP on how Palestine should be governed. Such diversity in goals makes defining reference points difficult-but not impossible.

Palestinian respondents were asked, "Define the group you support (Hamas, Fatah, PFLP, DFLP, etc.), and define the goals of this group." In response, supporters spoke of a primary issue that serves as a core reference point-a liberated Palestine. Beyond national liberation, respondents provided differing perspectives relating to the way Palestine should be administered after liberation. For example:

"Fatah is not an ideological party or movement. This group is not related to religion or ideology. It is a movement for national liberation, to bring back our identity. National liberation is the first and only goal right now." (Palestine 3) 
"[For the DFLP] the main goal is the freedom of Palestine. But we also have future goals about how we should live and solve problems ... we see one country in all of Palestine, one country-one people, Jewish or otherwise." (Palestine 5)

"[For the Islamic groups] one of the main goals is to worship one god. Palestine has a special condition; the Israelis occupy us. If we are to worship one god we need peace. So we seek to bring back the land to the Palestinian people under our religion. This land is only for the people that believe in god." (Palestine 8)

Using these goals to define the reference point, the respondents were asked to assess the past conditions (before the peace processes) to determine a past frame of reference. Supporters in both cases indicated that past social conditions fell short of the goals (i.e., the reference point). Therefore, they did perceive the past status quo as incongruent with their reference point, indicating the presence of a losses frame. This conclusion, however, is to be expected because the reference point is based on a non-status quo condition (a goal), which will automatically indicate the presence of perceived losses. Unexpectedly, 60 respondents $(84.5 \%$ of the supporters) persisted in this perception of losses despite recently negotiated peace agreements (the Good Friday Agreement in Northern Ireland and the Oslo Accords in Palestine).

Respondents were asked to assess present conditions (post-agreement period) with respect to the goals. Most supporters clearly indicated that the agreements had brought no change to the situation. Many believed that the agreements had actually moved conditions further away from the goals. For example:

"What peace agreement? No there has been no change overall. In fact I would say we are further away." (Northern Ireland 14)

"Oslo actually sacrificed part of historical Palestine. It legitimized Israeli supremacy and terrorism over the occupied lands. Oslo also aimed to legitimize the historical claims of Zionism by distinguishing the reality of Israel, while also promoting the view that Arabs were not equal to the Jews." (Palestine 1)

Eleven supporters indicated that the agreements were a step forward. These respondents recognized the shortcomings of the agreements but considered them to be a starting point:

"I think we were further away from our goals before the agreement. I think this cautiously though; I do have reservations about whether Republican goals are going to be realized within the agreement. But I hope, and would like to think, that we have come closer." (Northern Ireland 35) 
"It has created changes in the political conditions. In the beginning it was the armed struggle and now it is not. For me the armed struggle is not the way now. We should try the peace process to achieve our goals." (Palestine 7)

In sum, supporters identified a reference point that was incongruent with their perceptions of the status quo conditions - a losses frame, which is destabilizing to the status quo. The perceptions of loss remained strong among the majority of supporters $(84.5 \%)$ despite the existence of negotiated peace plans. A few of the supporters $(15.5 \%)$ recognized a sort of change stemming from the peace processes that altered the conduct of the conflict but did not resolve the issues of the conflict. Consequently, 66 of the supporters (93\%) indicated that they would continue to support armed struggle if a new round of violence were to erupt. Among those indicating continuing support for violence, most responded as follows:

"The armed struggle is a strategy within the whole, and it should take a back seat to the political struggle at the moment, which is moving forward. I personally would like to see the political struggle keep working, and because of my kids I do not want them to go through what I had to. But at the same time, if all efforts of a peaceful strategy are ignored or refused ... then it is inevitable for the armed struggle to continue, whether it be five years or ten years from now. It is only a matter of time before the armed conflict starts up again." (Northern Ireland 13)

Among respondents opposed to violent options (nonsupporters), we found that they classified goals differently but were consistent in the definition of past conditions as defined by losses. The following comments best represent their definition of goals:

"The establishment of political structures on the island of Ireland which would rule the whole to take sovereign responsibility of their own future and as much as you can in a globalizing world. I would see a nationalist goal as building structures on the island, which would rule the people with cooperation and agreement to benefit everyone. That may mean of course one parliament or it could mean three parliaments, it could mean a parliament in the North and in the South, and then an overall federal type structure. ... Certainly we support Irish unity by consent. And I believe that is what the people want. I would not see myself as a staunch territorial supporter. We need some form of constitutional arrangement on the basis of consent for unity." (Northern Ireland 37)

"I think that our goal is for national reconciliation. A state for Palestine. We can have this state and our rights within the boundaries of Israel. I believe that the Jews can and would live under a state that was Palestinian controlled." (Palestine 28) 
Using these goals to define the reference point, nonsupporters were asked to assess present social conditions in order to illustrate a frame of reference. Of the 11 nonsupporters, 9 claimed that the current condition (post-agreement period) was closer to the desired goals. Only two nonsupporters (18.2\%) indicated that the current agreement did not bring any change (as opposed to $84.5 \%$ of supporters indicating no change):

"We were at a position of strength and we made too many concessions to Israel. Surrender. I feel that those who negotiated the settlement should have discussed, or gotten a consensus from the population about what things should be talked about before going." (Palestine 16)

"It depends on the functioning of the new institutions and the economics within them. If they really change things then we will have seen change. It really depends on the future development within the agreement." (Northern Ireland 15)

This finding is telling; it indicates that most nonsupporters were in a neutral or gains frame, which creates stability as it reinforces the status quo. At the same time, respondents indicated that current conditions are closer to the goals, implying that they were further from the goals in the past-hence a losses frame. The following comments demonstrate this point:

"Given the agreement, we could say that nationalist goals are nearer now than they were in the past." (Northern Ireland 37)

"Partly yes. I know that it [Oslo] has not given us everything we want, and I know that we cannot reverse everything at once. I think it has achieved part of our goals." (Palestine 28)

Overall, these data show that supporters and nonsupporters held consistent perceptions regarding past losses. The current situation, though, represents a change for nonsupporters. This presents two questions. First, if both supporters and nonsupporters viewed past conditions as a loss, why did they vary in their support for rebellion? Second, why did perceptions regarding the current situation vary? The answers to these questions lie within how the two groups defined their goals.

Nonsupporters presented a wide array of goals centering on a general set of principles: equality (social and political), communal peace and unity, and an agreed resolution concerning the governance. Supporters shared these goals but had the additional goal of territoriality. For the Republican movement, supporters desired a united Ireland as part of the package of goals; a liberated Palestine was part of the package for supporters in Palestine.

The issue of territoriality is important for two reasons. First, supporters tied the value of the territorial claim to all other goals. In other words, supporters suggested that if the territorial claim were resolved, the other issues would likely be resolved as well. In contrast, nonsupporters generally held territorial claims as less important than the more pressing issues of equality, peace, and self- 
governance. Second, territorial claims are more contentious because of state opposition; concessions of territory are therefore less likely than social or political concessions (Herb, 1999; Knight, 1988; Toft, 2001). Because territorial issues are less likely to be resolved in the short term, individuals who give greater weight to territorial issues are likely to remain longer in the domain of losses, even when negotiations begin to resolve other nonterritorial issues. Hence, the constellation of goals is different by the degree to which the territorial issue remains central among the individual's goals. The following comment from a nonsupporter demonstrates the difference in goal definition:

"Our goal is to have the people on the island as a whole to live under one government. Whatever that government is. Should it be a 32-county republic, or what we have at the moment. It is whatever the people of the island want." (Northern Ireland 39)

Compare this to the comment of a supporter from the same case:

"The people saw the British as opposed to a united Ireland, opposed to equality; can a Catholic get equality within the system as it is? This means that the nationalist question comes up again because we tried to get change within the system, and we did not get it. The only way we are going to get it is through restructuring of the entire system, which has to be in the form of a united Ireland." (Northern Ireland 2)

Neither comment contradicts the other. Rather, the supporter simply placed territorial claims at the center, whereas the nonsupporter deemphasized territory as a core goal.

Further illustration of this point is found in a comparison of both groups' views of the status quo after the peace agreements. Supporters on average did not see the peace processes as harbingers of success. More than $80 \%$ stated that no change had occurred with the peace deals, whereas $82 \%$ of nonsupporters believed that change had occurred. Why the difference? Supporters were likely to view the peace deals as a letdown because they essentially sacrificed the territorial imperative. The Good Friday Agreement placed union status of Northern Ireland on hold for 7 years and then tied the status to a referendum. For Republicans, this sacrificed the core goal of a united Ireland. For nonsupporters, this solution was good because it offered the "agreed-upon" governance of the island. The Oslo Accords (I \& II and subsequent negotiations) turned over Gaza and limited territories in the West Bank to Palestinian control. However, the agreement left the majority of historical Palestine under the control of Israel and offered no movement regarding Jerusalem or the issue of Palestinian refugees. To supporters, this agreement was less a peace deal and more like surrendering. However, for nonsupporters, the agreement transfers limited control over limited territory and is thus a step toward the desired goals of self-rule. 
In sum, nonsupporters perceived past conditions in terms of losses, but the issue of territoriality distinguished their definition of losses from that of supporters. Supporters placed territorial demands as the centerpiece of reforms needed to resolve the conflict, whereas nonsupporters were willing to sacrifice territorial demands in exchange for communal peace, social equality, and agreed-upon governance. The question then becomes: How does this difference in goal definition affect one's willingness to accept or reject rebellious options?

\section{Weighting Options}

The interview data illustrate that individuals perceived social conditions before the peace processes in terms of losses, but supporters and nonsupporters defined losses differently. How does this difference in definition relate to one's willingness to accept or reject risks associated with rebellious action? The decision weight attached to options, combined with the frame of reference, determines which options individuals are likely to choose. Therefore, the goal is to illustrate the structure of the decision and how options are viewed by supporters versus nonsupporters.

For individuals willing to accept risky (violent) options, the decision weights flow with the most weight given to the outcome deemed certain, and undue weight is attached to the option where the outcome is less likely. Therefore, options are defined by competing losses-one certain, the other risky. Turning to the option with the heaviest weight (the certain outcome), the goal is to illustrate how supporters define social conditions absent any type of activity (i.e., accepting the status quo). Supporters were asked, "If you did not support the armed struggle, in your opinion would conditions improve, remain the same, or get worse?" All supporters stated that conditions would stay the same if they did not support the violent option. Because supporters believe that past and present conditions represent a loss, we can surmise that these individuals believe existing losses are certain to continue. Therefore, for supporters, doing nothing results in a certain outcome, and that outcome is defined by losses.

What does the alternative look like? The alternative for supporters is to accept violence as a way to escape losses. Is this option necessarily risky, and how is it risky? One element of risk relates to the possibility of escaping losses. The exact probabilities regarding successful rebellion are unknown. Historically speaking, rebellious action is not likely to achieve its goals (Gurr, 1988, p. 135). However, the success or failure of rebellion in other cases has little if any bearing on the probability of successful rebellion in Palestine or Northern Ireland. Cases of rebellion are not a linked unitary game where success can be determined to occur once in every six tries. Therefore, we must extrapolate from what is known about the likelihood that rebellion will succeed, and use this as a baseline for assessing the likelihood that rebellion would succeed in these cases. Given the history of rebellion, we can safely assume it to be a high-risk option, as rebellion has generally 
failed over time. Combining this with personal assessments of the success of rebellion in these cases, we note that $84.5 \%$ of supporters indicated that armed struggle did not achieve the stated goals-hence the persistence of perceived losses in the face of ongoing peace processes. Thus, armed struggle has been a high-risk option, as it has not proven successful in escaping losses according to the supporters interviewed here.

Another element of risk is the threat to personal safety. Participation in rebellious action (or mere support of it) involves considerable risk to personal safety because of government response to rebel movements (Lichbach, 1995). All supporters concurred with this assessment, which raises the question of whether such an understanding of risk weighs on the decision to support violent action. Supporters were asked, "Does your perception of the risks involved with armed struggle affect your decision to support its use to achieve your goals?" In response, 47 supporters $(66.2 \%)$ reported that they did not consider the threat to personal safety in the decision. Meanwhile, $15(21.1 \%)$ did consider the risks but only in a transitory way, meaning that costs are considered but dismissed quickly. Overall, nine supporters did consider the risks of support/participation. Among those considering risks, we find comments similar to the following:

"When people decide to join the IRA, the IRA will usually send them away at least once, and often ... two and three times. The IRA wants to make sure that people think the decision through and that it is carefully planned and they understand everything involved. Many people do take these different risks into consideration, they do think about what they are doing and then proceed to get involved." (Northern Ireland 6)

"When I graduated from the university I was nearly six years in the movement and in my military training. I was painfully aware of the risks involved with my decision. I was arrested in Jordan and I was injured twice in Jordan. I have fragments in my hand and in my head. I saw the risks with my own eyes and experience, regardless of this I did not question my involvement for one day." (Palestine 29)

In sum, supporters acknowledged that support/participation in rebellious action does entail threats to personal safety. However, among those interviewed, 62 $(87.3 \%)$ downplayed these risks completely or considered them only in a transitory way. Only $9(12.7 \%)$ took stock of the risks involved before proceeding to support the violent movement.

When considering the information here, we observe all supporters indicating that inaction will result in conditions remaining the same (i.e., accepting sure losses). At the same time, $84.5 \%$ of supporters recognized that rebellion has not led to a recovery of losses. Also, all recognized that support/participation results in threats to personal safety, but $87.3 \%$ admitted to dismissing these risks rather quickly. In sum, these data suggest that the likely outcomes associated with the 
risky options are given less weight than they deserve. How is the unlikely outcome perceived?

Supporters were asked, "Do you feel the armed struggle will succeed in achieving [Republican goals / an independent Palestine]?" Forty-six of the 71 supporters $(64.8 \%)$ gave a firm yes to this question. Eighteen respondents $(25.3 \%)$ gave a qualified yes, stating that the armed struggle was not the entire strategy, but rather one tactic within a larger political movement. For example: "Not by itself. The armed struggle was always part of a larger political movement. It was never meant to be the only part of the movement" (Northern Ireland 2); "Any soldier knows that war will not do anything by itself. Negotiations are needed" (Palestine 37). In short, 64 respondents $(90.1 \%)$ believed that violent action would succeed or be part of a successful strategy, and only 7 (9.9\%) believed armed struggle would not succeed. Moreover, an overwhelming majority (93\%) declared their intent to support violent options in the future to achieve nationalist goals. This finding is consistent with the loss aversion assumption of prospect theory, whereby individuals continue in efforts to recover losses longer than what is considered rationally acceptable. This point is best demonstrated by the upsurge in violence starting in September 2000 in the West Bank and Gaza Strip as well as in Israel, referred to as the al-Aqsa intifada. As such, these data illustrate the tendency of supporters to give undue weight to rebellious options as a way to escape losses.

For those withholding support for violent options, the structure of the decision is different. Although past conditions are viewed similarly in terms of losses, violent action is also perceived as a loss. This perception extends in part by the way goals are defined, as illustrated here:

"I think it comes to a hierarchy of principles and desires that build into a total view. Clearly we are short of that now. But in terms of people issues, we favor peace. We have become much less focused on territory and more focused on people. I think we are about uniting the people of Ireland, which makes the territory issue less relevant. Nationalism has moved beyond purely territorial issues." (Northern Ireland 30)

As the issue at hand is less territorially defined, the perceived utility of violence decreases. As the respondent suggests, the issues revolve more on "people issues" (previously defined as communal peace, equality, and governance). To advocate violence to achieve these goals contradicts the core issue of communal peace. Hence, violent options are viewed as contributing to existing losses, rather than as an option for recovering losses.

Overall, the framing of options changes and reflects the constellation of goals presented by nonsupporters. In this framed decision, the choice is to accept current conditions (defined by unmet goals and accepting communal violence as a way of life) or to gamble for improved conditions (by seeking nonviolent methods for conflict resolution). Such a definition of the options will invoke inaction biases among nonsupporters. 
Nonsupporters were asked, "Do you feel that by withholding support for armed struggle you are better aiding the nationalist cause?" In response, nonsupporters all stated that by withholding support they are advancing nationalist issues in a way that reflects their definition of nationalist goals. For example:

"There was a negative side to it. We do not need to kill other people to get our point across. This did more to prevent a solution than it did to help." (Palestine 28)

"I think the armed struggle itself is an obstacle to the achievement of my definition of nationalist goals-realization of equality and identity. I think those goals have been impeded by the armed struggle. Whatever the actions of the IRA it has impeded the actualization of nationalist goals." (Northern Ireland 5)

"I think it [withholding support] helps to accomplish these goals. Sure armed struggle is the easy way out, but it does not help the situation at all. It would help to have the SDLP [Social Democrat and Labour Party] and Sinn Féin sitting down and helping each other, instead of having one use politics and the other using armed struggle." (Northern Ireland 28)

"They could have put the gun down in the past and come to an agreement in the past. But they did not. It has proven that in the last 30 years the armed struggle has not worked." (Palestine 16)

Such comments illustrate the point that nonsupporters perceive violent options differently from supporters. Nonsupporters tend to see violent options as a barrier to achieving the stated goals. In essence, violence creates loss that is destabilizing to the status quo, reinforcing movement away from it. Movement away from the status quo takes the form of nonviolent measures-protest demonstrations, negotiation, and engagement in legal political processes.

\section{Discussion and Conclusions}

This study illustrates how individual definition of the reference point relates to a willingness to accept or reject violent options to recover losses. The key is that in ethnonational conflicts, territorial issues appear to be an important factor in individual willingness to accept rebellion. This finding is consistent with Toft's (2001) theory of territory and ethnic violence. The gist of the argument suggests that national identity is dependent on territory, which provides tangible evidence of the nation's existence (Herb, 1999). However, the data only illustrate these points on an individual level. Further research is needed to confirm this finding. At the same time, the data presented here do not speak to other issues relating to rebellious collective action. For instance, in what way do individual experience, socialization, and the impact of significant events play into a person's definition of reference points and willingness to accept or reject risk? The interview data 
presented here do not explore these issues, suggesting a need for further research.

Another issue to be explored relates to the activities of rebel organizations in mobilizing potential participants. The explanation laid out here suggests that groups frame options for individuals, yet no data exist to suggest that such activity takes place in rebellious situations. Another potentially interesting line of research relates to the differences in reference point definition and forms of behavior for groups engaging in risky action. For instance, the Palestinian groups display variations in goals with regard to the way an independent Palestine should be governed, and they speak to different audiences. Does this have any relationship to the forms of behavior we observe among these groups? Do specific goals (reference points) have any relationship to Fatah's and the DFLP's reliance on guerrilla tactics, or the Islamic groups relying on bombings and suicide bombings?

Critical assessments are needed as well. If we are to assume that territorial issues matter to the existence and persistence of rebellious action, then research is needed in cases where rebellion has ended or declined precipitously in the absence of any resolution on territorial matters. Some potential cases to explore could include the collapse of the Quebec Liberation Front or the Basque Euzkadi ta Azkazatuna (ETA) movement in Spain.

Prospect theory offers a new line of research with regard to rebellious collective action. But the full force of its applications and potential validity require further exploration before it can be hailed as a possible replacement for standard collective action and resource mobilization models.

\section{APPENDIX: Interview Schedules}

The following open-ended questions were presented to respondents in Northern Ireland and in the West Bank and Gaza Strip. In some cases, question content is case-specific. In those cases, the different forms of the question are labeled as [Northern Ireland] or [Palestine].

\section{Identity}

How would you describe your national background? (response options: [Irish, Northern Irish, British] [Arab, Palestinian Arab, Arab Israeli])

What factors would place another person in your identity group (for example, religion, language)?

What factors would exclude a person from your identity group?

\section{Identifying Goals, Losses Frame, and Levels of Support}

[Northern Ireland] Consider the following statement: "To be a Republican (nationalist) means that I believe the only acceptable state of existence is a 32- 
county (united) Ireland. Anything less is unsatisfactory and should be opposed." Explain whether or not you feel this statement accurately describes Republican (Nationalist) attitudes, and whether or not this statement accurately reflects you opinions or feelings on the issue.

[Palestine] What group do you support? (Hamas, Fatah, PFLP, DFLP) Could you define the goals of the group you support?

Considering the past condition [pre-Good Friday Agreement] [pre-Oslo], were you closer to, or further away from, your goals?

In the current situation (post-peace agreement) are you closer to, or further away from, your group's goals?

Do you support armed struggle as an appropriate tactic to achieve your group's goals?

(Supporters)

How much of your time is consumed with your activities to support armed conflict?

Do you consider your support or use of armed conflict to be a violation of the law?

Do you feel there a high risk of being arrested, injured, or killed for your support of armed conflict?

(Nonsupporters)

What types of activities do you engage in or support for achieving nationalist goals?

In your opinion, is the armed conflict alternative a high- or low-risk alternative for achieving nationalist goals?

Does armed conflict have a positive or negative impact on the attainment of nationalist goals?

(All respondents)

Does your perception of the risks involved with armed conflict affect your decision to support its use to achieve group goals?

(Supporters)

Do you feel the armed struggle would lead to [a united Ireland] [an independent Palestine]?

How risky do you think it is to support the armed struggle?

What would happen if you did not support the armed conflict? In your opinion would conditions: improve, remain the same, or get worse?

Is it not likely that you could get harassed, arrested, or killed if you continue to support the armed struggle? (Does this influence your decision to support armed conflict?)

(Nonsupporters)

Do you feel your lack of support for the armed struggle negatively affects the accomplishment of your group's goals?

Would you consider it too risky to support the armed struggle? (Why or why not?) 
In your opinion would political options be more likely or less likely to accomplish nationalist goals?

Given the current peace process, are you now less likely to support armed resistance to achieve nationalist goals?

If a new round of violence were initiated would you support it?

\section{Demographics}

Gender:

Education: (Number of Years)

Occupation:

Average Income:

Religious Affiliation:

$$
\text { Female }
$$

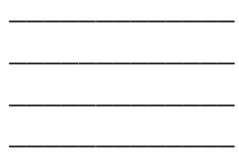

Male

\section{ACKNOWLEDGMENTS}

This research was made possible by the W. K. McClure Fellowship for International Peace. I thank the editors of Political Psychology and the anonymous reviewers for their comments and suggestions during the review process. Correspondence concerning this article should be sent to Daniel Masters, Department of Political Science, Marshall University, Smith Hall 779, Huntington, WV 27555. E-mail: mastersd@marshall.edu

\section{REFERENCES}

Baron, J., \& Ritov, I. (1994). Reference points and omission bias. Organizational Behavior and Human Decision Processes, 59, 457-498.

Berejikian, J. (1992). Revolutionary collective action and the agent-structure problem. American Political Science Review, 86, 647-657.

Berejikian, J. (2002). Model building with prospect theory: A cognitive approach to international relations. Political Psychology, 23, 759-786.

Gurr, T. R. (1988). Empirical research on political terrorism: The state of the art and how it might be improved. In R. O. Slater \& M. Stohl (Eds.), Current perspectives on international terrorism (pp. 115-154). London: Macmillan.

Gurr, T. R. (1996). Minorities, nationalities, and ethnopolitical conflict. In C. A. Crocker, F. O. Hampson, \& P. Aall (Eds.), Managing global chaos: Sources of and responses to international conflict (pp. 53-77). Washington, DC: U.S. Institute of Peace Press.

Hall, J. (1993). Ideas and the social sciences. In J. Goldstein \& R. O. Keohane (Eds.), Ideas and foreign policy: Beliefs, institutions, and political change (pp. 31-54). Ithaca, NY: Cornell University Press.

Herb, G. H. (1999). National identity and territory. In G. H. Herb \& D. H. Kaplan (Eds.), Nested identities: Nationalism, territory, and scale (pp. 9-30). Lanham, MD: Rowman \& Littlefield.

Kahneman, D., \& Tversky, A. (1979). Prospect theory: An analysis of decision under risk. Econometrica, 47, 263-291.

Kameda, T., \& Davis, J. H. (1990). The function of the reference point in individual and group risk decision making. Organizational Behavior and Human Decision Processes, 46, 55-76. 
Knight, D. B. (1988). Self-determination for indigenous peoples: The context for change. In R. J. Johnston, D. B. Knight, \& E. Kofman (Eds.), Nationalism, self-determination, and political geography (pp. 117-134). New York: Croom Helm.

Levi, A. S., \& Whyte, G. (1997). A cross cultural exploration of the reference dependence of crucial group decisions under risk: Japan's 1941 decision for war. Journal of Conflict Resolution, 41, 792-813.

Levy, J. S. (1997). Prospect theory, rational choice and international relations. International Studies Quarterly, 41, 87-112.

Levy, J. S. (2000). Loss aversion, framing effects, and international conflict. In M. I. Midlarsky (Ed.), Handbook of war studies II (pp. 193-221). Ann Arbor, MI: University of Michigan Press.

Lichbach, M. I. (1995). The rebel's dilemma. Ann Arbor, MI: University of Michigan Press.

Maoz, Z. (1990). Framing the national interest. World Politics, 43, 77-110.

McDermott, R. (1998). Risk-taking in international politics: Prospect theory in American foreign policy. Ann Arbor, MI: University of Michigan Press.

McGuire, T. W., Kiesler, S., \& Siegel, J. (1987). Group and computer-mediated discussion effects in risk decision making. Journal of Personality and Social Psychology, 52, 917-930.

Olson, M., Jr. (1990). The logic of collective action in Soviet-type societies. Journal of Soviet Nationalities, 1 (Summer), 8-27.

Paese, P. W., Bieser, M., \& Tubbs, M. E. (1993). Framing effects and shifts in group decision making. Organizational Behavior and Human Decision Processes, 56, 149-165.

Ritov, I., \& Baron, J. (1995). Outcome knowledge, regret, and omission bias. Organizational Behavior and Human Decision Processes, 64, 119-127.

Schweitzer, M. (1994). Disentangling status quo and omission effects: An experimental analysis. Organizational Behavior and Human Decision Processes, 58, 457-476.

Seibert, S. E., \& Goltz, S. M. (2001). Comparison of allocations by individuals and interacting groups in an escalation of commitment situation. Journal of Applied Social Psychology, 31, 134-156.

Smith, C. D. (1992). Palestine and the Arab-Israeli conflict. New York: St. Martin's.

Snow, D. A., \& Benford, R. (1992). Master frames and cycles of protest. In A. D. Morris \& C. Mueller (Eds.), Frontiers in social movement theory (pp. 133-155). New Haven, CT: Yale University Press.

Snow, D. A., Rochford, E. B., Jr., Worden, S. K., \& Benford, R. D. (1986). Frame alignment process, micromobilization, and movement participation. American Sociological Review, 51, 464-481.

Tilly, C. A. (1978). From mobilization to revolution. Reading, MA: Addison-Wesley.

Toft, M. D. (2001, April). A theory of territory, indivisibility, and ethnic violence. Paper presented at the Post-Communist Politics and Economics Workshop, Harvard University.

Tversky, A., \& Kahneman, D. (1981). The framing of decisions and the psychology of choice. Science, $211,453-458$.

Tversky, A., \& Kahneman, D. (1986). Rational choice and the framing of decisions. Journal of Business, 59, S251-S278.

Tversky, A., Slovic, P., \& Kahneman, D. (1990). The causes of preference reversal. American Economic Review, 80, 204-217.

Whyte, G. (1993). Escalating commitment in individual and group decision-making: A prospect theory approach. Organizational Behavior and Human Decision Processes, 54, 430-455. 